\title{
Recycling of vulcanized waste rubber through halogenations and amination chemical reactions
}

\author{
Y. A. Aggour ${ }^{1,2}$, A. S. Al-Shihri ${ }^{1}$ \& M. R. Bazzt ${ }^{1}$ \\ ${ }^{I}$ Chemistry Department, College of Science, King Khalid University, \\ P.O. Box 9004, Abha, Saudi Arabia \\ ${ }^{2}$ Chemistry Department, College of Science, Mansoura University, \\ New Demiatta, Egypt
}

\begin{abstract}
Pollution of the environment with scrap vulcanized rubber causes significant problems, due to the rubber's resistivity to natural conditions. This work deals with the chemical modification of waste vulcanized rubber, especially scrap tires, using chlorination and amination reactions. Chlorination of scrape-powdered tires was carried out in an aqueous and in a non-aqueous medium, passing through a continuous stream of $\mathrm{Cl}_{2}$ gas. A high yield of chlorinated waste rubber is obtained in the case of the aqueous medium using $\mathrm{HOCl}$ and $\mathrm{HClO}_{4}$ solutions. Amination reactions of the highly chlorinated waste rubber sample were achieved, using different primary, secondary and tertiary amines at 150,175 and $200{ }^{\circ} \mathrm{C}$, for two and three hours respectively. Characterizations of recycled waste rubber are performed using the IR, DSC, and SEM methods. A suggested mechanism of the reactions has been given.
\end{abstract}

Keywords: waste rubber, chemical modifications, recycling, thermal characterization.

\section{Introduction}

Recently, recycling of waste materials has become of growing importance for all industries in the world. Rubber products, such as those used in the automotive and transportation industries, are the biggest consumers of new rubber. Vehicular tires constitute the most important single items in terms of volume. In 
industrialized countries, rubber tires alone account for $60 \%$ of the total rubber consumption. With an increase in automobile and bicycle production, huge quantities of waste rubber tires are turning into waste mountains. In modern cars, besides the tires, it is possible to find more than 500 different rubber parts, whose total weights varies from 30 to $45 \mathrm{~kg}$ [1]. The remaining $40 \%$ of the rubber waste is mainly from the shoe making industry. Other waste rubber produced consists of rubber parts, washers, insulation material in electrical applications, packaging... etc. and constitutes a smaller proportion. The recycling rate of car tires is fast declining due to the failure of new technologies to penetrate the market as well as the collapse of the reclaiming sector industries. For these reasons, major quantities of rubber tires are stock piled and dumped on land and cause environmental pollution. Chemical processes for reusing rubber are of interest to reduce this problem. Reclaiming of rubber by devulcanization has been attempted $[2,3]$. The significant reclamation processes are the digester heating and mechanical processes. Carbonization in order to obtain carbon black is achieved at about $1200^{\circ} \mathrm{C}[4,5]$. The surface modification of rubber powder using a proprietary reactive gas atmosphere was studied [6]. Many chemical treatments of unvulcanized waste rubber are carried out, such as chlorination $[7,8]$ and sulfonation $[9,10]$. However, for the vulcanized waste rubber, the chemical treatments are few and insufficient $[11,12]$. This work is concerned with the halogenation reaction of waste rubber (WR) in different conditions, followed by the amination reactions using different amines, at various times and temperatures. The resulting materials are characterized by FT/IR, DSC and SEM analysis. The aim of this research is to convert WR to ion exchangers to remove hazardous ions from wastewater, which are now understudies in our laboratory.

\section{Materials and methods}

\subsection{Materials}

The finally ground disordered tire rubber with an average particle size of 0.2-0.4 $\mathrm{mm}$ was prepared from waste tires SBR (styrene-butadiene rubber) (USA) which contain about $60 \%$ SBR and $40 \%$ additives. The primary, secondary and tertiary amines used are of analytical grade (Aldrich), sodium hypochlorite (Aldrich), and perchloric acid (Fluka). The other chemicals and solvents were reagent grade and used as received.

\subsection{Apparatus}

IR spectroscopy has been carried out using a JASCO FT/IR 460 plus. Scanning electron microscopy (SEM) (6360 (LA)) was used to study the morphology of the products. A differential scanning calorimeter (DSC), Shimadzu DSC-50, was used to investigate the thermal behavior of the samples. 


\subsection{Preparation of waste rubber samples}

Waste rubber samples were prepared by the grinding of old tires, after removing the wires and fibers. Then, the rubber powder was washed several times by ether and hot distilled water followed by soaking in petroleum ether, acetone chloroform and chlorobenzene respectively, to remove the additive and harmful material from the waste rubber. Finally, the samples were swelled in $\mathrm{CCl}_{4}$ for $24 \mathrm{~h}$ before use.

\subsection{Chlorination methods}

Chlorination of WR was performed by two methods. The first one was carried out in an aqueous medium, by soaking the samples in chlorinated $\mathrm{CCl}_{4}$ for $24 \mathrm{~h}$, followed by impregnation in a chlorinated aqueous saturation solution of perchloric acid for another $24 \mathrm{~h}$. (or in an aqueous mixture of $\mathrm{HClO}_{4}$ and $\mathrm{HOCl}$ ). Then, a continuous stream of $\mathrm{Cl}_{2}$ gas was passed through the samples for $4 \mathrm{~h}$ at $40^{\circ} \mathrm{C}$, and for $6 \mathrm{hr}$ at $60{ }^{\circ} \mathrm{C}$ respectively. The samples were washed well with distilled water and then dried in air for two days. The second method was carried out in a non-aqueous medium by soaking these samples in $\mathrm{CCl}_{4}$ and $\mathrm{HOCl}$, then a continuous stream of $\mathrm{Cl}_{2}$ gas was passed through the samples for $4 \mathrm{~h}$ at $40^{\circ} \mathrm{C}$ and at $60^{\circ} \mathrm{C}$ for another $4 \mathrm{~h}$. Washing and drying were completed as mentioned above.

\subsection{Amination reaction of the chlorinated samples}

The substitution reaction of chloride atoms in the highly chlorinated samples by different amines has been carried out. The reaction was completed in a closed steel reactor and in the presence of excess amines at different times, and varied temperatures of 150,175 and $200^{\circ} \mathrm{C}$. The amines used are ethyl amine, diethyl amine, phenyl amine, diphenyl amine, triethyl amine, triethanol amine and propane diamine. The aminated obtained samples were converted into basic forms by adding an excess of $1 \mathrm{~N} \mathrm{NaOH}$ and then left for $24 \mathrm{~h}$ at room temperature. This was followed by washing with distilled water until the samples became free from excess base and they were then dried at $105^{\circ} \mathrm{C}$. The salt form of the resulting ion exchangers were obtained by impregnation of the basic form of the resulting materials in $1 \mathrm{~N} \mathrm{HCl}$ for three days, and then the samples were washed well with distilled water and dried at $105^{\circ} \mathrm{C}$.

\subsection{Calculations}

Chlorine in the samples was determined using the Houben method [13]. The $\mathrm{Cl}$ $\%$ was calculated as the following:

$$
\mathrm{Cl} \%=\mathrm{m} / \mathrm{g} \times 100
$$

where $\mathrm{m}$ is the mass of chloride determined per $\mathrm{gm}$, and $\mathrm{g}$ is the mass of halogenated samples per gm.

The yield percentage of chloride was determined based on the fact that $\sim 15 \%$ of the waste rubber was solubilized in $\mathrm{CCl}_{4}$ and other solvents used during the 
samples preparations. In addition, WR contains $\sim 60 \%$ styrene butadiene (about $70 \%$ of these values are butadiene). Amines were determined by back titration using an excess of $0.1 \mathrm{~N} \mathrm{HCl}$.

\section{Results and discussions}

\subsection{Chlorination reaction}

The addition of $\mathrm{Cl}_{2}$ is mainly done at the butadiene double bonds of waste rubber [14]. The chlorination reaction of waste rubber is performed in aqueous and in non-aqueous media under atmosphere pressure and at 40 and $60^{\circ} \mathrm{C}$ for 4 and $6 \mathrm{~h}$ respectively. Then, a continuous stream of $\mathrm{Cl}_{2}$ gas was passed through the reaction mixture (as described in section 2.4). The chloride is determined in each case and the results summarized in table 1 .

Table 1: Dependence of $\mathrm{Cl} \%$ and chloride (yields \%) on the treatment conditions of $\mathrm{WR}$ at 40 and $60^{\circ} \mathrm{C}$ for 4 and $6 \mathrm{~h}$ respectively.

\begin{tabular}{|c|c|c|c|}
\hline No. & treatment conditions & $\mathrm{Cl} \%$ & Yield \% \\
\hline 1 & non-aqueous medium of $\mathrm{CCl}_{4}$ and $\mathrm{HOCl}$ & 24.8 & 60.0 \\
\hline 2 & non-aqueous medium of $\mathrm{C} \mathrm{Cl}_{4}$ & 23.4 & 55.0 \\
\hline 3 & aqueous medium and $\mathrm{HClO}_{4}$ & 28.0 & 66.6 \\
\hline 4 & aqueous medium and $\mathrm{HOCl}$ & 8.30 & 16.5 \\
\hline 5 & aqueous medium of $\mathrm{HClO}_{4}$ and $\mathrm{HOCl}$ & 36.2 & 102.0 \\
\hline
\end{tabular}

As is shown in table 1 , the higher percentage of $\mathrm{Cl}_{2}$ is observed in the case of an aqueous medium using $\mathrm{HOCl}$ and $\mathrm{HClO}_{4}$. However, at temperatures higher than $60^{\circ} \mathrm{C}$, the concentration of $\mathrm{Cl}_{2}$ was decreased. The result of other studies by Falazi et al. [14], showed a similar behavior. Samples with a higher percentage of chloride atoms are used for studying the amination reaction at different conditions as will be described in the following sections.

\subsection{Amination reaction of the chlorinated waste rubber}

The highly chlorinated waste rubber samples were treated by the following different amines: ethylamine, phenyl amine, diphenylamine, triethyl amine, triethanol amine and propane diamine, at different times and temperatures [15]. The results are shown in table 2 .

As shown in table 2, the higher amine percentage was found in the case of propane diamine at $150^{\circ} \mathrm{C}$ for $2 \mathrm{~h}$. The basic form of the resulting ion exchangers are obtained by adding excess $1 \mathrm{~N} \mathrm{NaOH}$. A similar result was obtained by Mallah [15] was observed for the amination of waste rubber using ethylene diamine. The chloride salt form of ion exchanger is obtained by impregnation of the sample in $1 \mathrm{~N} \mathrm{HCl}$ for three days at room temperature. Similar results can be obtained by the reaction of ammonia or pyridine with halogenated WR [16].

A suggested reaction mechanism of the chlorination and amination reactions on the waste rubber is given in figure 1 . 
Table 2: Dependence of amine percentage on rubber, times and temperatures, using various amines.

\begin{tabular}{|l|c|c|c|c|}
\hline No. & types of amine & $\mathrm{T}^{\circ} \mathrm{C}$ & $\mathrm{t}(\mathrm{h})$ & $\%$ amine \\
\hline 1 & ethyl amine & 150 & 2 & 37.6 \\
\hline 2 & ethyl amine & 175 & 2 & 8.50 \\
\hline 3 & ethyl amine & 200 & 2 & 9.70 \\
\hline 4 & phenyl amine & 150 & 4 & 5.30 \\
\hline 5 & phenyl amine & 175 & 2 & 7.30 \\
\hline 6 & phenyl amine & 200 & 4 & 3.20 \\
\hline 7 & diethyl amine & 150 & 2 & 9.00 \\
\hline 8 & diethyl amine & 175 & 2 & 10.5 \\
\hline 9 & diethyl amine & 200 & 4 & 13.8 \\
\hline 10 & diphenyl amine & 150 & 2 & 5.90 \\
\hline 11 & diphenyl amine & 175 & 2 & 7.20 \\
\hline 12 & triethyl amine & 150 & 2 & 10.6 \\
\hline 13 & triethyl amine & 175 & 2 & 8.80 \\
\hline 14 & triethyl amine & 200 & 4 & 13.8 \\
\hline 15 & triethanol amine & 150 & 2 & 16.0 \\
\hline 16 & triethanol amine & 175 & 2 & 9.20 \\
\hline 17 & triethanol amine & 200 & 4 & 8.00 \\
\hline 18 & propane diamine & 150 & 2 & 40.2 \\
\hline 19 & propane diamine & 175 & 2 & 39.5 \\
\hline 20 & propane diamine & 200 & 4 & 39.0 \\
\hline
\end{tabular}

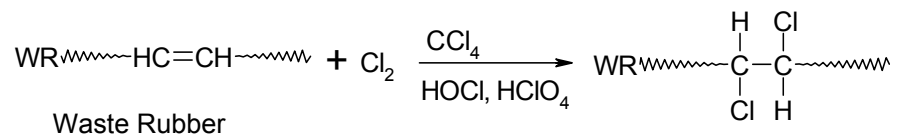

Chlorinated waste rubber

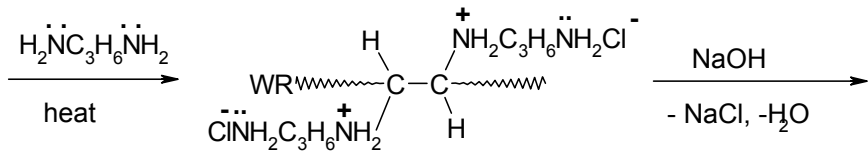

Aminated waste rubber

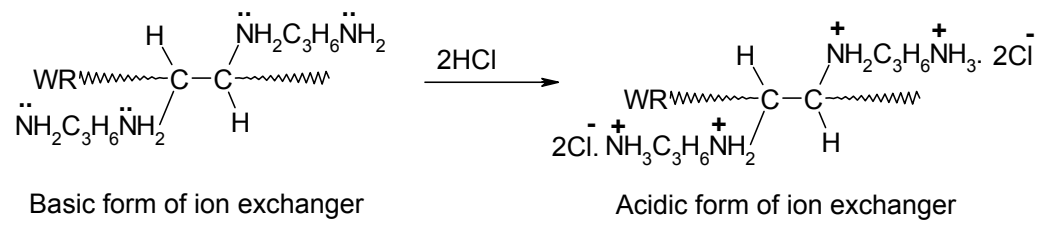

Figure 1: Chlorination and amination reactions of waste vulcanized rubber. 


\subsection{Characterization of modified waste rubber}

\subsubsection{FT/IR spectroscopy}

The FT/IR spectra of waste rubber, chlorinated waste rubber and aminated waste rubber are shown in figure 2. The spectrum of waste rubber in figure 2(a) shows the presence of an olefinic double bond of butadiene at frequency $v_{\mathrm{C}=\mathrm{C}}=1625$ $\mathrm{cm}^{-1}$. In figure $2(\mathrm{~b})$, it is possible to observe the vibration stretching signal $v_{\mathrm{c}-\mathrm{cl}}$ at $625 \mathrm{~cm}^{-1}$. In the case of the spectrum of aminated waste rubber bands, the vibration stretching signal can be observed at $1440 \mathrm{~cm}^{-1}$, which could be attributed to $v_{\mathrm{NH} 3+}$ deformation. Also, the appearance of two bands at 1033-1086 was observed due to $v_{\mathrm{C}-\mathrm{N}}$ stretching bands of primary amines [17]. Although the spectra of waste rubber are not easy to study due to its various additives, the spectra are helpful in indicating the additives of $\mathrm{Cl}_{2}$ to the butadiene double bond and the substitution reaction of chloride atoms by amines.

(a)

(b)

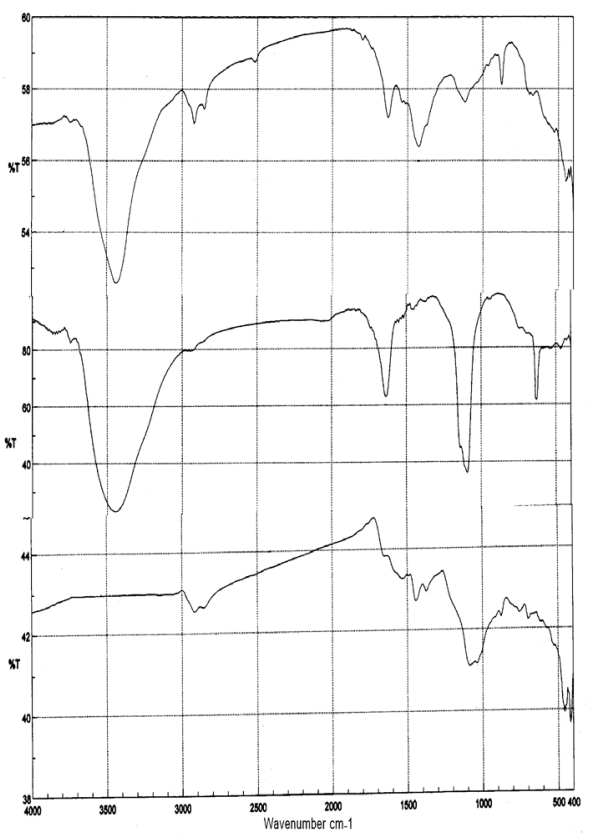

Figure 2: $\quad$ FT/IR spectra for WR (a); chlorinated waste rubber (b), and aminated waste rubber (using propane diamine) (c).

\subsubsection{Thermal studies}

The DSC thermogram obtained for waste rubber is shown in figure 3(a), it illustrated three exothermic peaks at $252^{\circ} \mathrm{C}, 351^{\circ} \mathrm{C}$ and $505^{\circ} \mathrm{C}$, and two endothermic peaks at 282 and 406 respectively. Based on the reaction transition temperature of exotherms and endotherms, the transition pyrolysis temperature ranges can be set at $206-282,283-406$ and $407-500^{\circ} \mathrm{C}$. The first regions due to the major product of pyrolysis are dipentene, and the second are due to $\mathrm{C} 4$ 


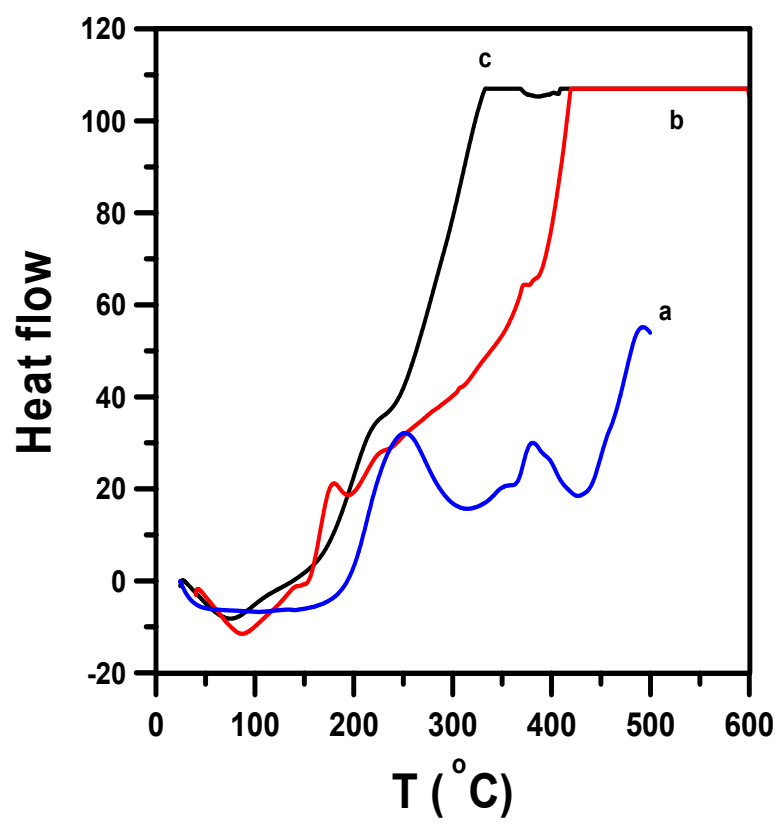

Figure 3: DSC curves of WR (a), chlorinated -WR (b) and aminated -WR (c).

(a)

(b)

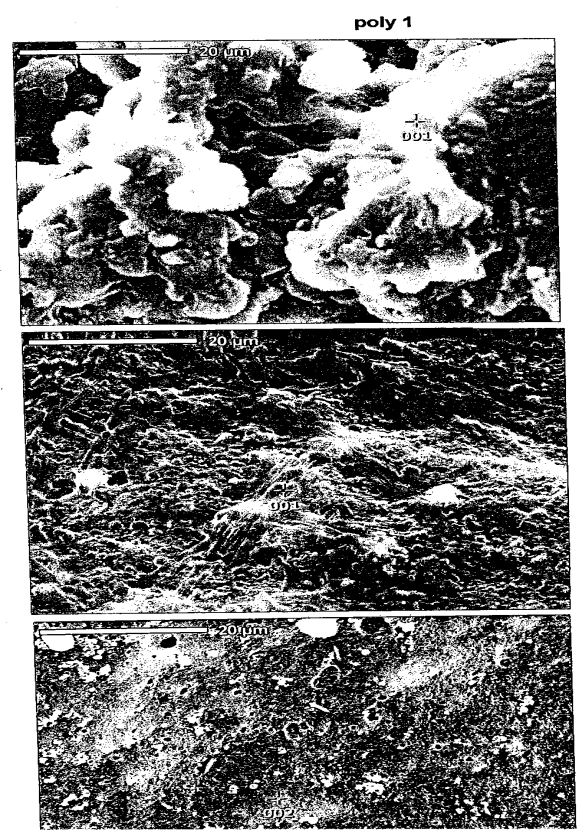

Figure 4: $\quad$ Scanning electron microscope (SEM) image of (a) waste rubber; (b) chlorinated waste rubber and (c) aminated waste rubber. 
hydrocarbons. The yields of aromatic hydrocarbons increased up to $406-500^{\circ} \mathrm{C}$, giving high yields of $\mathrm{CH}_{4}, \mathrm{C} 2$ and $\mathrm{C} 3$, indicating that complete decomposition of rubber, as reported by Chen and Qian [18] and by Miguel et al [19].

On the other hand, the DSC curves for chlorinated-WR and aminated-WR are illustrated in figure 3(b) and (c) respectively. They show small peaks and shifting to lower temperatures, indicating that the crystallinity of rubber is decreased with the chemical treatments [19].

\subsubsection{Morphology}

The SEM micrograph of waste rubber shows an inhomogeneous structure due to various industrial additives onto rubber (figure 4(a)). As far as the SEM micrographs of chlorinated waste rubber are concerned, the morphology is significantly different from that of waste rubber and the structure becomes homogenous and the particles size decreases (figure 4(b)). Figure 4(c) indicates the SEM micrograph of aminated waste rubber, in which the homogeneity is increased as result of the introduction of diamine into the structure of chlorinated waste rubber, and the particles size is further decreased. From SEM and DSC studies, the crystallinity of waste rubber is decreased by the chlorination and amination reactions.

As a continuation of this work, we are using the resulting ion exchanger to remove the different pollutant anions from industrial wastewater.

\section{Conclusions}

The recycling of waste rubber can be performed by chemical modification methods. Chlorination reactions of WR were achieved in both aqueous and nonaqueous mediums. Highly chlorinated samples were obtained in the case of an aqueous medium of $\mathrm{HClO}_{4}$ and $\mathrm{HOCl}$. Amination reactions of highly chlorinated samples have been carried out using different amines. Relatively high aminated waste rubber was obtained in using a propane diamine. The chloride salt form of the resulting ion exchanger will be used to remove some toxic anions from wastewater. The resulting materials are characterized by FT/IR, DSC and SEM analysis.

\section{Acknowledgements}

The authors gratefully acknowledge financial support from King Abdulaziz City for Science and Technology KACST (Project number AP-25-18). The authors also thank the technical staff at KKU for their help with this work.

\section{References}

[1] Ahmed, R. \& Klundert, A. Rubber Recycling, 20 th WEDC conference, Colombo, Sr. Lanka, 1994.

[2] Paul, John, Encyclo. Polym. Sci. Eng., 14, pp.787, 1988.

[3] Vohwinkel K., Kautsch. Gummi. Kunstst., 44(8), pp. 47,1991. 
[4] Scott C.E., U.S.3, 700, pp. 615, Oct. 24, 1972.

[5] Beckman J.A., U.S. 3,729, pp.223, 1974.

[6] Bauman B.D., ACS, Rubber Division Meeting, Chicago, Illinois, April 20, paper No.25, 1994.

[7] Encyclopedia of polymer science and technology V, 2, N.Y. - (a, o), 1965.

[8] Kiripichikou, P.A., Averko, L.A., Chemistry and technology of synthetic rubber, Moscow, 1970.

[9] Pemiv., Technology of modified synthetic rubber, Moscow, 1964.

[10] Tager, A. Physical chemistry of polymers, Mir, publishers, Moscow pp.65, 1978.

[11] Falazi, B., Abdel-Malek, S., J. Saudi Chemical Society, 4 pp. 353,2000.

[12] Abdel - Bary, E., Falazi, B., and Yehia, A., " $3^{\text {rd }}$ Arab international conf. in polymer science technology. Vol.2, pp.636, 1995.

[13] Houben, Weyl, Methods of organic chemistry, Lzdateistvo chemie, Moscow, p.1032, 1967.

[14] Falazi, B., Bazet, MR, Mahfoz, A. and Subai, A., J. Alleppo Uni. For science, series of basic science 24 pp. 193-214, 1997.

[15] Mallah, A., Msc. Thiese Uni. Alleppo. Fac. Sci., Syria, 2004.

[16] Falazi B., \& Subai, A., J. Damaccus Uni. For science, series of basic science, 17(1), pp. 95-108,2001.

[17] Parik, V.M., (eds) Absorption spectroscopy of organic molecules, Addition, wesley publishing company1974,

[18] Chen, F., \& Qian, J., Studies of the thermal degradation of waste rubber ". Waste Management, 23, pp. 463-467, 2003.

[19] Miguel, G.S., Aguado, J., Serrano, D.P. \& Escola, J.M., Thermal and catalytic conversion of used tyre rubber and its polymeric constituents using Py-GC/MS. Applied Catal. B: Environ. 64, pp. 209-219, 2006. 